Article

\title{
The Role of Organic Farming for Improving Food Security from the Perspective of Fars Farmers
}

\author{
Laleh Morshedi, Farhad Lashgarara *, Seyed Jamal Farajollah Hosseini and \\ Maryam Omidi Najafabadi \\ Department of Agricultural Extension and Education, Science and Research Branch, Islamic Azad University, \\ Tehran, Iran; L.morshedi@srbiau.ac.ir (L.M.); Jamalfhosseini@srbiau.ac.ir (S.J.F.H.); \\ M.omidi@srbiau.ac.ir (M.O.N.) \\ * Correspondence: F.lashgarara@srbiau.ac.ir
}

Received: 16 July 2017; Accepted: 8 November 2017; Published: 14 November 2017

\begin{abstract}
This study was designed to evaluate the role of organic farming in improving food security from the perspective of farmers in the Fars province of Iran. The research method was practical in terms of its purpose, non-experimental in terms of the data collection, and correlational in terms of the data analysis. The study population comprised 622 farmers who were members of plant pathology clinics in Fars province of which 187 of them were selected as the sample size by the use of Cochran's formula through a proportional stratified sampling method. The research tool was a questionnaire for which validity was confirmed by experts and its reliability by Cronbach's alpha coefficient (0.704-0.982). The results revealed that farmers (45.5\%) viewed their food security at an average level. The estimated standardized regression coefficients in the model showed that, from the farmers' perspective, the most effective capabilities in improving food security were technical (0.747), health and safety (0.735), and the optimization of production (0.628), respectively.
\end{abstract}

Keywords: food security; social; economic; environmental dimension; organic farming

\section{Introduction}

One of the most important problems of the world in the 21st century is food security [1]. In Iran, on one hand, providing food for the growing population requires a tremendous increase in the level of agricultural production [2] and, on the other hand, given the importance of food security and the irreparable damage due to excessive use of agricultural chemicals, attention has been paid to organic farming [3].

The International Federation of Organic Agriculture Movements (IFOAM) defines organic farming as a production system that maintains soil health, ecosystems, and humans. According to Lampkin, organic farming can be defined as "an approach to agriculture which aims at social, environmental and economic sustainability and animal welfare by minimizing the use of external resources, maximizing the use of locally-derived renewable resources and agro-ecosystem management and using the market to compensate for internalizing external costs" [4,5]. Organic farming is based on minimizing the use of external inputs, fertilizers, insecticides, and pesticides [6].

As defined by the World Food Summit in 1996, "food security" exists when all people at all times have adequate physical and economic access to enough safe and nutritious food to meet their needs for a healthy and active life [7]. Food security is a complex process that involves dimensions such as availability, access, utilization, and stability [8].

Owing to the high population of 7 billion people in the world, the dispute over the ability of organic farming to feed the world is high. Generally, large biotechnology companies, especially those that benefit from the use of pesticides and genetically-modified seeds, have raised the question of whether organic farming can feed the world or not. According to the FAO, the applicability of organic farming 
on production is dependent on the previous farming systems. An over-simplification of the impact of the transition to organic farming on yields shows that, in developed countries, organic systems decrease yields; the range is dependent on the intensity of the external inputs used before conversion; in the so-called Green Revolution areas (irrigated lands), conversion to organic agriculture usually leads to almost identical yields; and in traditional rain-fed agriculture (with low external inputs), organic agriculture has the potential to increase yields [9]. Evaluation of the benefits and limitations of organic agriculture on food security is complex. The effect of the transition to organic practices will depend on the farmer and farming society, their skills, and the resources accessible to them. Organic agriculture can increase productivity, especially in situations where farmers are vulnerable to food shortages; it can increase income through higher financial value, and lower prices paid for inputs, or the combinations of these three. The variety of production in organic agriculture decreases the risk of crop failure and relevant food security and economic problems [10]. Organic agriculture is a sustainable and environmentally friendly production system that offers developing countries a wide range of economic, environmental, and social benefits. Although organic farming systems produce yields less than conventional agriculture, they are more profitable to farmers because consumers are willing to pay more [11].

Organic agriculture has three dimensions-social, economic, and environmental-and these three dimensions can improve food security. In the social dimension, organic farming requires more compact work and has the potential to contribute to long-term employment in rural areas. Organic farming plays an important role in employment in rural areas because of the hiring of more seasonal workers and, given the increases in organic food sales, however, opportunities are likely to continue in the occupations related to organic foods. Organic farming promotes entrepreneurship and decreases immigration in rural areas, thus, it enables new and different groups in the society to be involved in agricultural activities and will help to improve employment. Additionally, organic farming recognizes the value of indigenous and traditional knowledge and combines indigenous knowledge with production procedures which enhances social capacity while empowering farmers and local communities, which is consistent with achieving food security $[9,10,12-14]$.

In the economic dimension, organic farming is a sustainable option for small farmers to improve food security and to enhance the overall performance of farm income, and it can be said that an increase in household income can increase food security. Organic farming reduces input costs besides the increase of the standards of living of small and marginal farmers [12,15-21]. Organic farming is cost-effective for farmers due to the lack of usage of chemicals (due to its expensive price), turning to inexpensive methods, such as biological resources rather than chemical fertilizers and pesticides. Other reasons that persuade farmers towards organic farming is the raising of product prices and consequently-increased profits from the sale of these products and the lack of intermediaries to sell them [22]. Organic farming uses existing local assets rather than consuming capital resources intensively, so poor farmers can improve their farm productivity and fertility while avoiding dependence on expensive external inputs. Organic farming can increase productivity and income, thus helping to improve food security. There are a large number of economic opportunities that lead to the increase of added value of organic products through processing and marketing activities and the improvement of food security in the long-term [9,12,16-20,23,24].

In the environmental dimension, organic farming improves soil quality, secures farm future, and offers environmental protection. The fertile soil leads to stability and is effective in the production cycle. More nutrients given to the soil result in less soil erosion and increase soil biodiversity, which improves food security in the long-term $[20,25,26]$. Additionally, in organic farming with minimum tillage, biological fertilizers, proper crop rotation and cover crops, green manure, etc., an increase in soil fertility occurs [18]. Organic farming enhances food security by improving resistance to diseases and pests, combating desertification by reducing soil erosion and protecting water resources, and maintaining and improving environmental services. Avoiding chemical residues and pesticides and consuming fresh products, acquiring healthy diets, and taking advantage of the nutritional value of organic products are among other motivations that improve food security $[10,13,21,23,25-27]$. 
Agricultural practices coupled with the widespread usage of chemical synthetic materials have a negative impacts on agricultural production and human welfare. According to the evidence, the main goal of the current agricultural model in Iran on increasing production has failed to be successful in improving food security and environmental conservation and, subsequently, the need to change the model is felt. Since organic farming is in progress only in some parts of Iran, it can be argued that it is high time to consider the issue of organic farming in Iran seriously.

In general, Iran is in its primary steps of transitioning to organic products. Owing to its span, climate variety, and soil fertility, Fars province is considered as the major agricultural productive area in Iran with 74,000 hectares (ha) of organic crop farming, such as vegetables, figs, almonds, grapes, pomegranates, saffron [28]. Despite what is expected, based on the latest information on food security in the country, it is revealed that Fars province is relatively insecure in terms of the food security situation [29]. Considering the importance and potential of this province in agriculture, its pivotal role in providing food security and production of organic products in the region, as well as a relatively low level of food security, the aim of this study is to identify the role of organic farming in improving food security from the perspectives of farmers. Therefore, the objectives of the study are to: (1) survey and address the effect of social capability (capacity building, creating jobs) of organic farming in improving food security; (2) survey and address the effect of economic capability (optimization of production, economic benefit, income creation) of organic farming in improving food security; and (3) survey and address the effect of environmental capability (technical, protection, health and safety) of organic farming in improving food security from the viewpoint of Fars farmers.

\section{Materials and Methods}

The methods of analysis used in this applied study involved quantitative research and non-experimental (descriptive) research design. The population of the study comprised 622 farmers who cultivate strategic products, such as wheat, maize, and rice, which play a key role in food security, and were also members of plant pathology clinics. These clinics have official statistics of their cultivation and their numbers. In this research, organic products are products that have passed through the laboratory in order to determine the residual chemical content before being supplied to the consumer. These farms are also under the supervision of plant pathology clinics. In fact, samples of products from these farms were taken randomly by representatives of the University of Medical Sciences and the Standard Office in Shiraz and sent to the laboratory for determination of the remaining pesticides, and then applied for certification.

The sample was determined using Cochran's formula $\mathrm{n}=\mathrm{Nt}^{2} \mathrm{~s}^{2} / \mathrm{Nd}^{2}+\mathrm{t}^{2} \mathrm{~s}^{2}$. In the relation, $\mathrm{N}$ is the statistical population, and $t$ is the acceptable confidence coefficient obtained from the Student's $t$ table. In addition, $\mathrm{S}^{2}$ is the variance of the studied feature in the population, and $\mathrm{d}$ is the desired probability accuracy (half the confidence interval), so $\mathrm{n}=622 \times 3.88 \times 0.306 /(622 \times 0.0025)+(3.84 \times 0.306)=267$, and since $\mathrm{n} /(\mathrm{N})=0.47<05 / 0$, therefore, the adjustment formula was used in the following examples. $\mathrm{n}=\mathrm{N} /(1+\mathrm{n} / \mathrm{N})=267 /(1+267 / 622)=187$, so using this formula, the sample volume obtained was 187. In this study, the sampling used was a proportional stratified sampling method; therefore, according to the number of clinics, and in proportion to the population and sample within each clinic, samples were selected based on the number of farmers of those clinics. In the quantitative research, field study tools included a questionnaire. The content and face validity were established by a panel of experts comprising faculty members, and the Cronbach's alpha coefficient was used to measure the reliability of the questionnaire. Cronbach's alpha coefficient was obtained for all parts of the questionnaires (0.704-0.982) and this was indicative of the reliability of the tool (Table 1).

The dependent variable in this study was food security using the 23-items in four parts of availability (seven items), access (five items), utilization (six items), and stability (five items). The independent variables included the social dimension in two categories: capacity building (five items) and creating jobs (five items); the economic dimensions of organic farming in three categories: production optimization (four items), economic advantage (seven items), and income 
creation (seven items); and environmental aspects of organic farming in three categories: technical (six items), protection (12 items), and health and safety (seven items).

Table 1. Cronbach's alpha coefficient in each part of the questionnaire.

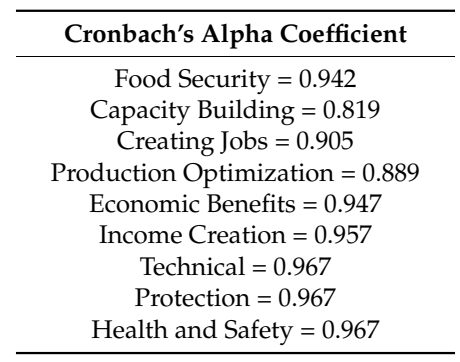

In this study, after collection and classification of data, data analysis was conducted in two parts, descriptive and inferential statistics. Criteria, such as the mean, median, and mode were used in the descriptive statistics of the research, and structural equation modeling (SEM) was used for the inferential statistics using the classical approach and, finally, the model was designed. SEM is a well-known technique for estimating, analyzing, and testing models. Figure 1 below illustrates the structure of the SEM. There are two kinds of variables, observed and latent variables (capacity building, creating jobs, production optimization, economic advantage, income creation, technical, protection, health and safety) in the model. In SEM, there are five steps. Step 1: model designing (done by drawing pictures using Amos software (IBM Corporation, Wexford, PA, USA) step 2: data collection for model testing (SPSS data file use); step 3: model estimation (this step is performed by Amos software); step 4: model assessment (fit statistics appear after the parameter estimates); and step 5: the final model presentation. The capability of organic farming in three dimensions of social, economic, and environmental in improving food security are prioritized based on the path coefficient estimate )estimate is one of the Amos's outputs that estimate the model's parameter and is equal to $\beta$ in regression) of the final model is taken from Amos software. Each part is shown in separate tables with details until the final model can be better understood. Information processing and statistical analysis of throughout the study was done using SPSS $\mathrm{V}_{20}$ (IBM Corporation, New York, NY, USA) and Amos $V_{23}$ software (IBM Corporation, Wexford, PA, USA).

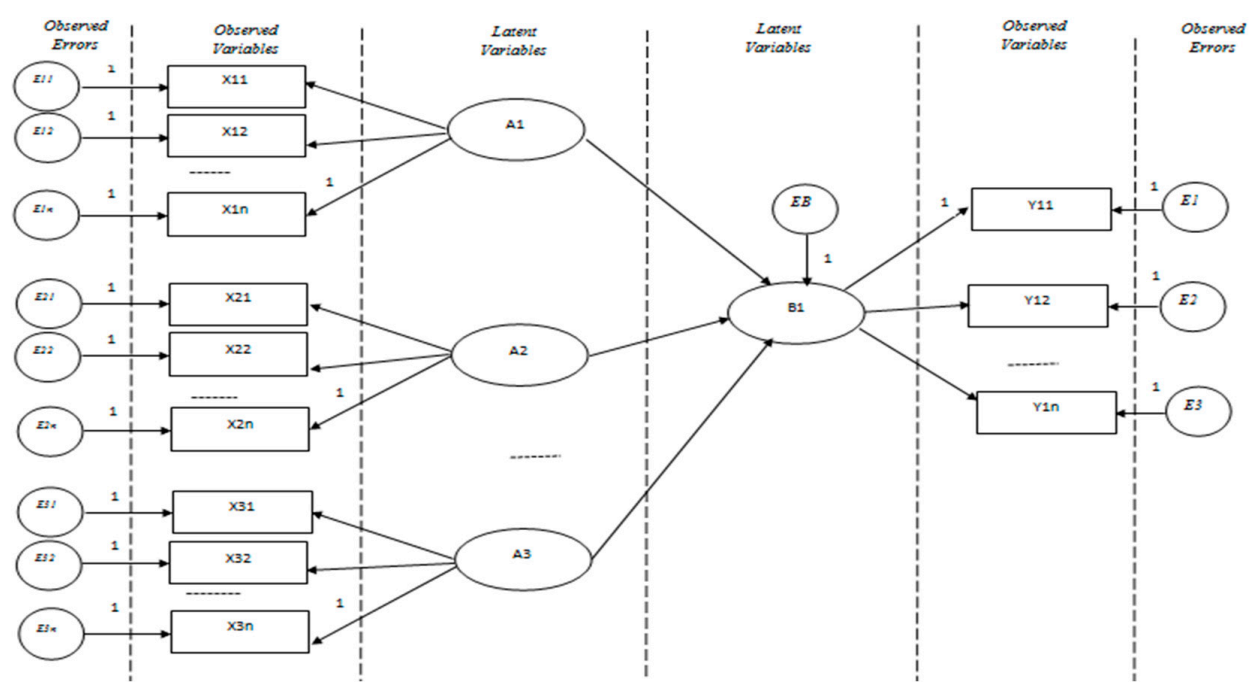

Figure 1. Structural equation model (SEM). 


\section{Results}

The youngest person in the population was 23 and the oldest was 71 years old, and the average age of the population was 48 years and the median was 49 years. A total of 182 farmers (97.3\%) were male and five $(2.7 \%)$ were female. Forty-eight $(25.7 \%)$ of the respondents had diplomas and $45(24.1 \%)$ had no formal education.

The dependent variable in this study was food security using the 23-items in four parts of availability (seven items), access (five items), utilization (six items), and stability (five items) which were assessed at the level of pseudo-distance with Likert's scale (very low: 1, low: 2, average: 3, high: 4, and very high: 5). All of these items were added and then re-coded together; the lowest and highest points for a responsive, respectively was $23=(1 \times 23)$ and $115=(5 \times 23)$. After re-coding, very low positions were allocated to the (23-40), low (41-59), medium (60-78), high (79-97), and very high (98-116). The research results revealed that the rate of food security from the perspective of the majority of respondents $(45.5 \%)$ was at the medium level, and $36.4 \%$ at the low level. Other findings are observable in Table 2.

Table 2. Farmers' points of view on food security $(n=187)$.

\begin{tabular}{cccc}
\hline Food Security & Frequency (Number) & Percent & Cumulative Percentage \\
\hline Very low (23-40) & 30 & 16 & 16 \\
Low (41-59) & 68 & 36.4 & 52.4 \\
Medium (60-78) & 85 & 45.5 & 97.9 \\
High (79-97) & 4 & 2.1 & 100 \\
Total & 187 & 100 & \\
\hline \multicolumn{4}{c}{ Mean $=3}$.
\end{tabular}

One of the food security dimensions is food availability. There are seven items in food availability. Based on the collected information; Table 3 illustrates farmers' viewpoints on food availability items based on mean and S.E.

Table 3. Frequency of distribution of farmers' viewpoints on food availability $(n=187)$.

\begin{tabular}{lcc}
\hline & Mean & SE \\
\hline Your organic agricultural production rate. & 3.09 & 0.024 \\
\hline Your arable land under cultivation of organic products. & 2.13 & 0.042 \\
\hline Your productivity in the production of organic products (the revenue than expenses) & 3.29 & 0.020 \\
\hline $\begin{array}{l}\text { Your usage rate of scientific principles in organic products (Using mulch, natural } \\
\text { pesticides, green manure, compost, crop rotation) }\end{array}$ & 3.47 & 0.026 \\
\hline Your participation rate in the courses of cultivation of organic products. & 3.60 & 0.030 \\
\hline $\begin{array}{l}\text { Your annual lose rate of organic products at planting, harvesting and processing stage } \\
\text { (Due to pests and diseases, untimely rainfall, non-normative harvest) }\end{array}$ & 2.66 & 0.031 \\
\hline $\begin{array}{l}\text { Your annual lose rate of organic products in producing stage due to inadequate transport, } \\
\text { non-normative relocation of products, etc.) }\end{array}$ & 2.20 & 0.041 \\
\hline
\end{tabular}

One of the food security dimension is food access. There are five items in food access. Based on the collected information, Table 4 illustrates farmers' viewpoints on food access items based on the mean and S.E.

Table 4. Frequency of distribution of farmers' viewpoints on food access ( $\mathrm{n}=187)$.

\begin{tabular}{lcc}
\hline & Mean & SE \\
\hline Your income level of producing organic products & 3.03 & 0.018 \\
Your purchasing power rate in the result of producing organic products. & 3.07 & 0.029 \\
The transport system quality for your organic products transfer. & 3.14 & 0.034 \\
Credit facilities allocated to you for producing organic products. & 2.90 & 0.040 \\
Allocated subsidies to you for producing organic products. & 2.48 & 0.042 \\
\hline
\end{tabular}


One of the food security dimensions is food utilization. There are six items in food utilization. Based on the collected information, Table 5 shows farmers' viewpoints on food utilization items based on the mean and S.E.

One of the food security dimensions is food stability. There are five items in food stability. Based on the collected information, Table 6 illustrates farmers' viewpoints on food stability items based on the mean and S.E.

Table 5. Frequency of distribution of farmers' viewpoints on food utilization ( $\mathrm{n}=187)$.

\begin{tabular}{lcc}
\hline & Mean & SE \\
\hline The use of organic products by yourself. & 3.01 & 0.035 \\
Reducing malnutrition rate by using your own organic products. & 2.97 & 0.045 \\
Your health status rate. & 3.19 & 0.027 \\
The quality of health and nutritional education services to your family. & 2.94 & 0.032 \\
The rate of intake of quality food by your family. & 3.29 & 0.024 \\
Food safety status in your family. & 3.45 & 0.021 \\
\hline
\end{tabular}

Table 6. Frequency of distribution of farmers' viewpoints on food stability ( $\mathrm{n}=187)$.

\begin{tabular}{lcc}
\hline & Mean & SE \\
\hline Damage rates which are caused by unstable climates. & 3.03 & 0.025 \\
The rate of incidence of pests and diseases to your organic products. & 3.82 & 0.032 \\
The rate of use of biological methods to sustain sources. & 3.33 & 0.019 \\
The possibility of lack of food access because of periodic events in your family & 3.25 & 0.024 \\
The organic products ability in securing food for future generation by considering the & 3.79 & 0.015 \\
least negative impact on the environment. & & \\
\hline
\end{tabular}

\subsection{Three Dimension of Organic Agriculture on Improving Food Security}

3.1.1. The Social Dimensions of Organic Farming (Capacity Building and Creating Jobs) to Improve Food Security

In the social dimension of organic farming, there are two categories: capacity building (five items) and creating jobs (five items). Statistics path coefficient estimates (Estimate is one of the Amos outputs that estimates the model's parameter and is equal to $\beta$ in regression) were used in order to prioritize the social dimension of capacity building and job creating capability in organic farming. Any item that has a higher path coefficient has a higher priority. In the capacity building capability of organic farming, the statement of valuing indigenous knowledge systems and traditional farming systems (Estimate $=0.91)$ and in the job creation capability of organic farming, the statement of improving employment opportunities, particularly in rural areas (Estimate $=0.83$ ) have the highest priority among the items in order to improve food security (Table 7).

Table 7. Prioritizing capacity building and job creation capability of organic farming to improve food security according to path coefficient estimates.

\begin{tabular}{clc}
\hline Priorities & \multicolumn{1}{c}{ Capacity Building } & Estimate \\
\hline 1 & Valuing indigenous knowledge systems and traditional farming systems & 0.91 \\
\hline 2 & Dependence on existing production assets locally & 0.88 \\
\hline 3 & Respect to local culture & 0.85 \\
\hline 4 & Creating self-reliance in production & 0.71 \\
\hline 5 & $\begin{array}{l}\text { Empowering rural communities through partnerships with other farmers to } \\
\text { form groups (providing participatory guarantee system and the strengthening } \\
\text { of social organization) }\end{array}$ & 0.67 \\
\hline Priorities & \multicolumn{2}{c}{ Creating Jobs } \\
\hline 1 & Improving employment opportunities, particularly in rural areas & Estimate \\
\hline
\end{tabular}


Table 7. Cont.

\begin{tabular}{lll}
\hline 2 & Increasing farm employment & 0.75 \\
\hline 3 & Attracting new entrepreneurs, as a result of the need to do more & 0.71 \\
\hline 4 & Increasing non-farm employment & 0.69 \\
\hline 5 & Involving new and different community groups in production and trade & 0.58 \\
\hline
\end{tabular}

3.1.2. The Economic Dimension of Organic Farming (Production Optimization, Economic Benefits, and Income Creation) to Improve Food Security

In the economic dimensions of organic farming, there are three categories: production optimization (four items), economic advantage (seven items), and income creation (seven items). Statistics path coefficient estimates (Estimate) were used to prioritize these categories. Any item that has a higher path coefficient has a higher priority. In the production optimization capability of organic farming, the statement of an improving efficiency in areas with low inputs (Estimate $=0.82$ ) and in the economic benefits capability of organic farming, the statements of satisfying farmers from an economic perspective (Estimate $=0.88$ ), and in the income creation capability of organic farming, the statement of reducing the cost of purchased external inputs (Estimate $=0.97$ ) have the highest priority among the items in order to improve food security (Table 8).

Table 8. Prioritizing production optimization, economic benefits, income creation capability of organic farming to improve food security according to path coefficient estimates

\begin{tabular}{|c|c|c|}
\hline Priorities & Production Optimization & Estimate \\
\hline 1 & Improving efficiency in areas with low inputs (pesticides, herbicides, etc.) & 0.82 \\
\hline 2 & Reducing crop damage & 0.81 \\
\hline 3 & Reducing risk of production & 0.73 \\
\hline 4 & Higher crop yield in drought years & 0.67 \\
\hline Priorities & Economic Benefits & Estimate \\
\hline 1 & Satisfying farmers from an economic perspective & 0.88 \\
\hline 2 & Added value of organic products through marketing activities and processing & 0.83 \\
\hline 3 & $\begin{array}{l}\text { Efficient usage of resources more efficiently (to minimize the use of } \\
\text { non-renewable resources) }\end{array}$ & 0.78 \\
\hline 4 & $\begin{array}{l}\text { Affordable than traditional agriculture (due to lower variable costs of inputs, } \\
\text { identical Fixed costs and higher prices of organic products) }\end{array}$ & 0.77 \\
\hline 5 & Market opportunities (marketing) for producers & 0.76 \\
\hline 6 & Greater economic profitability due to the use of domestic inputs & 0.76 \\
\hline 7 & Enhancing the overall performance of the farm in unit area & 0.67 \\
\hline Priorities & Income Creation & Estimate \\
\hline 1 & Reducing the cost of purchased external inputs (chemicals, pesticides, etc.) & 0.97 \\
\hline 2 & Cash savings by reducing cash costs of agricultural production & 0.86 \\
\hline 3 & $\begin{array}{l}\text { Improving the livelihoods of family farmers production (through the sale of } \\
\text { excessive production of organic products which enable them to provide better } \\
\text { clothes and better education opportunities for their children and other farmers) }\end{array}$ & 0.84 \\
\hline 4 & Welfare improvement of farmers engaging in organic farming & 0.82 \\
\hline 5 & Increasing farmers income in the long-term & 0.72 \\
\hline 6 & $\begin{array}{l}\text { Reducing the need for and dependence on credit facilities (loans) due to } \\
\text { inputs import }\end{array}$ & 0.70 \\
\hline 7 & Decrease in cash investments (reduction of import requirements) & 0.65 \\
\hline
\end{tabular}


3.1.3. The Environmental Dimension of Organic Farming (Technical, Protection, Health and Safety) to Improve Food Security

In environmental aspects of organic farming, there are three categories: technical (six items), protection (12 items), and health and safety (seven items). Statistics path coefficient estimates (Estimate) were used to prioritize the environmental dimension of technical, protection, and health and safety capabilities in organic farming. Any item that has a higher path coefficient has a higher priority. In the technical capability of organic farming, the statements of reducing tillage operations (Estimate $=0.94$ ) and using environmentally friendly production methods (Estimate $=0.84$ ); in the protection capability of organic farming, the statements of maintaining soil fertility in the long-term (Estimate $=0.76$ ) and improving soil structure (Estimate $=0.75$ ); and in the health and safety capability of organic farming, the statements of producing food without chemicals (Estimate $=0.85$ ) have the highest priority among the items in order to improve food security (Table 9).

Table 9. Prioritizing technical, protection, health and safety capability of organic farming to improve food security according to path coefficient estimates.

\begin{tabular}{|c|c|c|}
\hline Priorities & Technical & Estimate \\
\hline 1 & Reducing tillage operations & 0.94 \\
\hline 2 & $\begin{array}{l}\text { Using environmentally friendly production methods (such as the use of animal } \\
\text { products, intercropping, use of mulch, using natural pesticides, crop residue } \\
\text { returned, green manure, compost, crop rotation) }\end{array}$ & 0.84 \\
\hline 3 & Non-usage of chemical pesticides, additives etc. & 0.75 \\
\hline 4 & Recycling plant and animal origin in order to return nutrients to the land & 0.71 \\
\hline 5 & Enriching soil carbon & 0.68 \\
\hline 6 & Reduction of mechanization (density less pressure by machinery) & 0.63 \\
\hline Priorities & Protection & Estimate \\
\hline 1 & Maintaining soil fertility in the long-term & 0.76 \\
\hline 2 & Improving soil structure & 0.75 \\
\hline 3 & Increasing soil water retention potential & 0.74 \\
\hline 4 & Products that have better resistance to pests and diseases & 0.73 \\
\hline 5 & Increasing soil permeability using frequency & 0.71 \\
\hline 6 & Protection of local and regional products & 0.70 \\
\hline 7 & Preservation of genetic diversity & 0.70 \\
\hline 8 & Protection of water resources (surface and groundwater) & 0.59 \\
\hline 9 & Reducing environmental pollution (pollution reduction of water, soil, and air) & 0.57 \\
\hline 10 & Greater diversification in the product due to the mandatory rotation & 0.53 \\
\hline 11 & $\begin{array}{l}\text { Helping to increase the adaptive capacity of agriculture (agri-environmental } \\
\text { stresses compatibility) }\end{array}$ & 0.49 \\
\hline 12 & $\begin{array}{l}\text { Improved resistance to climate variability (including variability of rainfall, } \\
\text { temperature, and other unforeseen incidents) }\end{array}$ & 0.47 \\
\hline
\end{tabular}


Table 9. Cont.

\begin{tabular}{clc}
\hline Priorities & \multicolumn{1}{c}{ Health and Safety } & Estimate \\
\hline 1 & Producing food without chemicals & 0.85 \\
\hline 2 & Promoting food safety & 0.82 \\
\hline 3 & Food production with better taste & 0.78 \\
\hline 4 & Minimizing disease risks in food & 0.78 \\
\hline 5 & Improving consumer health and individual health & 0.76 \\
\hline 6 & Reduction in risks of pesticide toxicity & 0.74 \\
\hline 7 & Production of healthy food of high-quality and high-value & 0.74 \\
\hline
\end{tabular}

\subsection{Fitness of the Model}

As the characteristics of fitness show in Table 10, the ratio of chi-square to degrees of freedom CMIN/DF was 1.102 and smaller than 2. P CMIN was 0.118 and greater than 0.05. Additionally, the estimated root mean square error of approximation (RMSEA) was 0.023, and smaller than 0.05, confirming the fitness of the model and representing the best fit to the model. Another way to fit this model is to calculate the approximate high goodness of fit index (GFI) and improve adjusted goodness of fit index (AGFI). The proximity of the amount to 0.95 is another confirmation to the fit of the model.

The parameters of the route are presented in Table 11, along with the significance level. It became obvious that technical pathways, health and safety, production optimization, income creation, protection, creating jobs, capacity building, and economic advantages are significant at 99\%. Directions standardized regression coefficients estimates are given in the table. As it is shown, a technical capability of 0.747 , with the highest effect, followed by health and safety with 0.735 , and the optimization of production with 0.628 create the greatest impact on improving food security.

Table 10. Goodness of fit measures for model evaluation.

\begin{tabular}{cccccccc}
\hline Goodness of Fit Measures & RMSEA & CMIN/DF & GFI & AGFI & NFI & CFI & Pcmin \\
\hline Amount & 0.023 & 1.102 & 0.911 & 0.818 & $0 / 927$ & 0.992 & $0 / 118$ \\
\hline
\end{tabular}

Table 11. Regression weight and significance test of paths.

\begin{tabular}{ccccc}
\hline & Estimate & $\begin{array}{c}\text { Stand Error } \\
\text { (S.E) }\end{array}$ & $\begin{array}{c}\text { Critical Ratio } \\
\text { (C.R) }\end{array}$ & $\begin{array}{c}\text { Significant Level } \\
(\boldsymbol{p} \text {-Value })\end{array}$ \\
\hline Technical $\rightarrow$ Food Security & 0.747 & 0.091 & 9.586 & $0.001^{* * *}$ \\
Health \& Safety $\rightarrow$ Food Security & 0.735 & 0.100 & 8.680 & $0.001^{* * *}$ \\
ProductionOptimization $\rightarrow$ Food Security & 0.628 & 0.121 & 6.242 & $0.001^{* * *}$ \\
Income Creation $\rightarrow$ Food Security & 0.574 & 0.117 & 6.048 & $0.001^{* * *}$ \\
Protection $\rightarrow$ Food Security & 0.543 & 0.123 & 5.338 & $0.001^{* * *}$ \\
Job Creation $\rightarrow$ Food Security & 0.508 & 0.107 & 5.797 & $0.001^{* * *}$ \\
Capacity Building $\rightarrow$ Food Security & 0.473 & 0.108 & 5.076 & $0.001^{* * *}$ \\
Economic Benefit $\rightarrow$ Food Security & 0.403 & 0.531 & 3.522 & $0.001^{* * *}$ \\
\hline
\end{tabular}

The structural equation model (SEM) for estimating the standard coefficients of organic agriculture in improving food security is illustrated in Figure 2. 


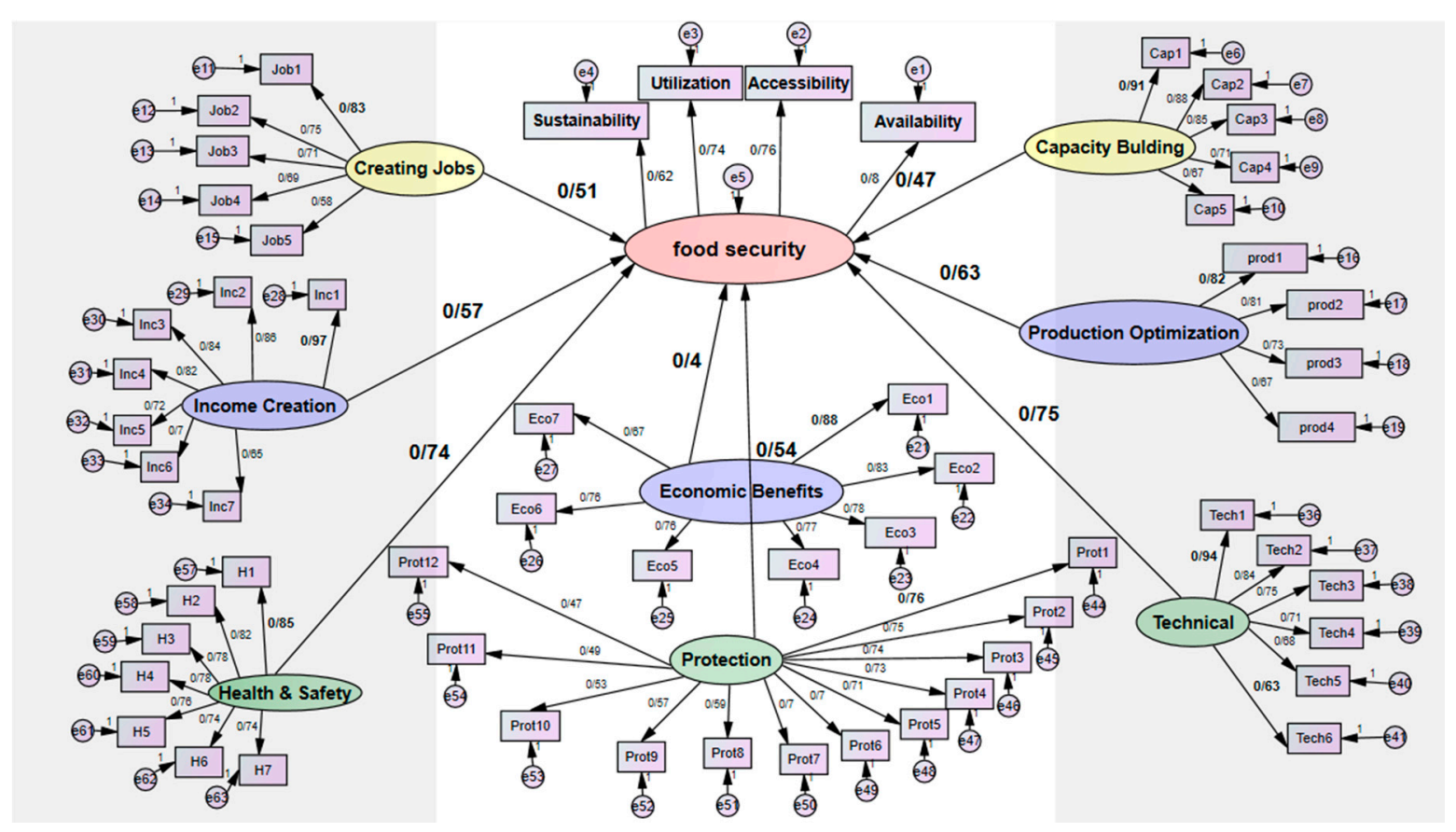

Figure 2. Food security in four parts of availability, access, utilization, stability, and organic farming was measured in three dimensions of social (capacity building, creating jobs), economic (production optimization, economic advantage, income creation), and environmental (technical, protection, health and safety) aspects from the farmers' perspective in order to achieve the final model of organic farming in improving food security in Fars province.

\section{Discussion and Conclusions}

The direct answer or simple solution on how to solve food insecurity through organic farming is very difficult and it is impossible to make simple statements. The acceptance level in order to improve the quantity and quality of food should be increased through organic agriculture. In this study, farmers' comments regarding the role of organic farming were studied in social, economic, and environmental dimensions for improving food security. The results indicated that the level of food security from the perspective of the majority of respondents $(45.5 \%)$ was at a medium level. From the perspective of farmers in the social dimension of organic farming, the standardized regression coefficient of the two capabilities of capacity building and job creation was 0.51 and 0.47 , respectively. According to the results of SEM, in the capacity building, the statement of valuing indigenous knowledge systems (0.88) and also in creating job capability, the statements of improving employment opportunities, especially in rural areas (0.83), have been the highest priority in improving food security. We conclude that, in the social dimension, paying attention to traditional knowledge in line with organic farming, which is based on the experience often tested over years of usage and adapted to the local culture and environment, is a very important item in improving food security. In addition, from the opinion of Fars farmers, since cultivating methods in organic farming are different from what is common in conventional agriculture, it makes use of more and new labor and involves farmers in agricultural activities. Supply of products to the market also leads to the creation of new employment opportunities, which will empower farmers and increase food security. The results are in agreement with the findings of [10,12-15].

With regard to economic dimension of the three capabilities of production optimization (0.628), economic benefits (0.403), and income creation (0.574) based on the results of SEM, improvement efficiency in areas with low inputs $(0.82)$ is the most important result of production optimization capability. Satisfaction of farmers (0.88) is the most important result of economic benefits capability 
and reducing the costs of purchased external inputs (0.97) is the most important result of income creation capability of organic farming. Therefore, based on the Fars farmers viewpoint in the economic dimension, organic farming reduces the cost of purchasing external inputs, as well as improving the production of a higher-value economic product with a more marketable export value, thus satisfying farmers economically. It improves their income and is heading towards improved food security in the long-term. The results are in agreement with the findings of [12,15-19,21-24,30].

The three technical, protection, and health and safety capabilities of the environmental dimension of organic farming standardized regression coefficient were $0.747,0.543$, and 0.735 , respectively. Based on the results of SEM in terms of technical ability in organic farming, the statements of reduced tillage operation (0.94) and the use of environmentally-friendly production methods (0.84), in terms of protection capability, the statements of maintaining soil fertility in the long-term $(0.76)$ and improving soil structure (0.75), and in terms of health and safety capability, food production items without any chemicals (0.85) have the highest priority in improving food security. Thus, in the environmental dimension, Fars farmers believed that organic farming improves soil the fertility process due to the use of green manure and reduced tillage operation and avoiding fertilizers and chemical pesticides, by the advantage of the nutritional value of organic products, improves food security in the long-term. The results are consistent with the findings of $[10,13,20,22,24,26-28,31]$. The direction of the standardized regression coefficient estimates showed that, from the perspective of farmers, a technical capability of 0.747 , with the highest effect, followed by health and safety of 0.735 , and the optimization of production of 0.628 in organic farming, create the greatest impact on improving food security. According to the findings of this study, we conclude that organic farming is one of the suitable methods to improve food security. From the farmers' perspective, the most effective capabilities in improving food security were technical, health and safety, and the optimization of production, respectively. These results show that farmers believed that the use of appropriate techniques of organic farming leads to the optimization of production and improves the health and safety of persons which, in the long-term, promotes food security.

It should be considered that we cannot use the global version for all cultivation in order to improve food security, but organic agriculture emphasis should be placed on the use of management operations because each ecosystem requires a particular management approach based on the environmental, social, and economic conditions.

Author Contributions: This manuscript was a part of Laleh Morshedi's Ph.D. thesis. Farhad lashgarara was the supervisor and also Seyed Jamal Farajollah Hosseini and Maryam Omidi Najafabadi were the advisors of the thesis. Laleh Morshedi wrote the manuscript, collected information, analyzed the data, interpreted the results and finalized the manuscript.

Conflicts of Interest: The authors declare no conflict of interest.

\section{References}

1. Lashgarara, F. Surveying the Role of Information and Communication Technologies (ICTs) to Improve Food Security of Rural Households from the Viewpoint of Agricultural Extension Experts. Ph.D. Thesis, Science and Research Branch, Islamic Azad University, Tehran, Iran, 2008.

2. Dinpnah, G.; Jamshid Nouri, A. Factors affecting feasibility of hydroponics cultivation based on infrastructure. J. Agric. Ext. Educ. Res. 2014, 26, 83-92.

3. Chaichi, B. Organic farming, healthy soil, healthy plants, healthy man. J. Livest. Agro-Ind. 2009, 117, 49-50.

4. IFOAM. Definition of Organic Agriculture. Available online: http:/ /www.ifoam.org/fr/organic-landmarks / definition-organic-agriculture (accessed on 10 September 2015).

5. Lampkin, N. Organic Farming, 1sd ed.; Farming Press Books: Ipswich, UK, 1990; ISBN 0852361912.

6. World Health Organization (WHO); Food and Agriculture Organization of the United Nations (FAO). Organically Produced Foods. Available online: http:/ ftp.fao.org/docrep/fao/010/a1385e/a1385e00.pdf (accessed on 14 October 2015). 
7. Food and Agriculture Organization of the United Nations (FAO). An Introduction to the Basic Concepts of Food Security. Available online: http://www.fao.org/docrep/013/a1936e/al936e00.pdf (accessed on 16 February 2015).

8. International Fund for Agricultural Development (IFAD); World Federation of Exchanges (WFE); Food and Agriculture Organization of the United Nations (FAO). The State of Food Insecurity in the World Food Insecurity in the World. Available online: http:/ / www.fao.org/docrep/018/i3434e/i3434e00.htm (accessed on 12 May 2013).

9. Food and Agriculture Organization of the United Nations (FAO). Can Organic Farmers Produce Enough Food for Everybody? Available online: http:/ / www.fao.org/organicag/oa-faq/oa-faq7/en/ (accessed on 20 February 2016).

10. Azadi, H.; Ho, P. Genetically modified and organic crops in developing countries: A review of options for food security. Biotechnol. Adv. 2010, 28, 160-168. [CrossRef] [PubMed]

11. Bawden, T. Organic Farming Can Feed the World If Done Right, Scientists Claim. Available online: http:/ / www.independent.co.uk/environment/organic-farming-can-feed-the-world-if-done-rightscientists-claim-9913651.html (accessed on 8 June 2014).

12. Peramaiyan, P.; Halberg, N.; Hermansen, J.E. Food security of small holding farmers comparing organic and conventional in India. J. Sustain. Agric. 2011, 1, 48-68.

13. Asadullah Pour, E. The Designing Behavior Pattern of Farmers in Organic Agriculture, Organic Agriculture and a Case of Rice Producers of Mazandaran Province. Ph.D. Thesis, Science and Research Branch, Islamic Azad University, Tehran, Iran, 16 September 2014.

14. Ward, C.; Reynolds, L. Organic agriculture contributes to sustainable food security. Vital Signs 2013, 20, 66-68.

15. Bahramian, S. The Role of Sustainable Agriculture in Improving Food Security of Rural Households from the Perspective of Agricultural Experts in Isfahan Province. Master's Thesis, Science and Research Branch, Islamic Azad University, Tehran, Iran, 11 August 2011.

16. Bahramian, S.; Mirdamadi, S.M. Organic agriculture, increase farmers' income. J. Barzgar 2011, 2, 3-4.

17. Johannsen, J.; Mertineit, A.; Wilhelm, B.; Buntzel-Cano, R.; Schöne, F.; Fleckenstein, M. Organic Farming: A Contribution to Sustainable Poverty Alleviation in Developing Countries? Available online: http:/ / www.naturland.de/fileadmin/MDB/documents/Publication/English/Organic_Farming_ Contribution_to_Sustainable_Poverty-Alleviation.pdf (accessed on 5 May 2014).

18. Asgharian Dastenaii, A. Determinants of Farm Household's Food Security in Kiar County. Master's Thesis, Agricultural Extension and Education University, Shiraz, Iran, 2 September 2010.

19. Chhabra, S. Social Capital, Social Support, and Food Insecurity in Food Pantry Users. Master's Thesis, University of Cincinnati, Cincinnati, OH, USA, 22 June 2012.

20. Omidi Najafabadi, M.A. gender sensitive analysis towards organic agriculture: A structural equation modeling approach. J. Agric. Environ. Ethics 2014, 27, 225-240. [CrossRef]

21. Khaledi, A.; Faryadras, V. Simulations of food security based on trade policy. J. Agric. Econ. 2011, 5, 61-79.

22. Saedi, J. Organic farming, necessity for a country. J. Anal. Predicat. Educ. 2011, 22, 5-8.

23. Torjusen, H.; Lieblein, G.; Wandel, M.; Francis, C.A. Food system orientation and quality perception among consumers and producers of organic food in Hedmark County, Norway. Food Qual. Preference 2001, 12, 207-216. [CrossRef]

24. Hoffmann, U. Assuring Food Security in Developing Countries under the Challenges of Climate Change: Key Trade and Development Issues of Fundamental Transition of Agriculture. 2011. Available online: http:/ / unctad.org/en/docs/osgdp20111_en.pdf (accessed on 12 November 2017).

25. Azadi, H.; Schoonbeek, S.; Mahmoudi, H.; Derudder, B.; De Maeyer, P.; Witlox, F. Organic agriculture and sustainable food production system: Main potentials. Agric. Ecosyst. Environ. 2011, 144, 92-94. [CrossRef]

26. Mojib Hagh Ghadam, Z.; Asgari Bazayeh, F. Weed and pest management in organic farming. J. Agric. Sustain. Dev. 2013, 52, 34-44.

27. Malakouti, J. Organic agriculture is the way of human salvation. J. Sabzineh 2014, 92, 15-16.

28. Portal of Fars Organization Agriculture Jihad. Status Report of Agricultural Sector. Available online: http:/ / www.fars.agri-jahad.ir/portal/home/ (accessed on 20 October 2014). 
29. Kolahdouz, F.; Najafi, F. System Monitoring National Food Security and Nutrition Security in Iran and Developed the First Map of the Food Security Situation in the Country, 1st ed.; Ministry of Health, Treatment \& Medical Education: Tehran, Iran, 2012; pp. 1-251. ISBN 9786005528268.

30. Rundgren, G. Organic Agriculture and Food Security. Available online: http:/ /www.ifoam-eu.org/sites / default/files/organic_agriculture_and_food_security_printcopy.pdf (accessed on 23 December 2016).

31. Miriam Inwood, S. Assessing Opportunities for Organic and Sustainably Grown Local Foods for Restaurant and Retail Food Store Distribution in Ohio. Master' Thesis, Ohio State University, Columbus, OH, USA, 1 March 2004.

(c) (

(C) 2017 by the authors. Licensee MDPI, Basel, Switzerland. This article is an open access article distributed under the terms and conditions of the Creative Commons Attribution (CC BY) license (http:/ / creativecommons.org/licenses/by/4.0/). 